\title{
A Cognitive Linguistics Study to Reveal the Concept of Death of Indonesian Indigenous Tribe
}

\author{
Nirwanto Maruf ${ }^{1}$, Rita Tanduk ${ }^{2}$ \\ ${ }^{1}$ Universitas Muhammadiyah Gresik, East Java, Indonesia \\ ${ }^{2}$ Universitas Kristen Indonesia Toraja \\ nirwanto.maruf@umg.ac.id, ritatanduk@ukitoraja.ac.id
}

\begin{abstract}
Despite of many previous studies related to conceptual metaphor have been conducted since George Lakoff and Mark Johnson have introduced their work known as Metaphor We Live By in 1980, but none of them have analysed oral discourse as their corpus. This study aims to reveal the concept of death belonging to one of the Indonesian indigenous tribes located in Sulawesi Island called Kajang tribe. The Kajang tribe has an ancient oral discourse which delivers orally from generation to generation known as Pasang ri Kajang, and it is full of metaphorical expressions. This present study employs the conceptual metaphor theory (CMT) introduced by Lakoff and Johnson (1980, 2003), and the approach of conceptual metaphor analysis (CMA) by Charteris Black (2004) to reveal the concept of death found in Pasang ri Kajang. This qualitative research obtained the data through semi-structured interviews, field observation, recording, and note-taking. The conceptual metaphor techniques comprising three CMA stages, namely identification, interpretation, and explanation, were used for data analysis. The results of the study indicate that the concept of death as found in Pasang ri Kajang is DEATH IS A JOURNEY. This conceptual metaphor gives a detailed description of death as a journey of the soul to the hereafter. This research concludes that people of Kajang believes only good souls are rewarded with eternal life (Karakkang) and extraordinary wealth (Kalumannyang kaluppepeang) in the hereafter (ahera).
\end{abstract}

Keywords

pasang ri kajang; concept of death; conceptual metaphor; conceptual metaphor analysis

\section{Introduction}

Dissimilar with the traditional views of metaphor which see metaphor only associated with literary language, cognitive linguistics consider our thinking is fundamentally metaphorical (Lakoff and Johnson, 1980, 1999). This leads us to draw a conclusion that metaphor is conceptual, anything we think and act are basically metaphorical (Evans and Green, 2006:44). Our everyday language are all metaphors in nature (Evans and Green, 2006:287).

Cognitive scientists such as Lakoff and Johnson (1980,1999, 2003), Kovecses (2005), and others argue that metaphors emerge in everyday way of thinking, and found in everyday language. In the cognitive linguistics view of points, the core of metaphors involves gaining an understanding as well as experience on a specific concept in relation to another, hence humans act according to individual perception (Lakoff and Johnson, 1980:5).

Conceptual metaphor is a system associated with the use of abstract concepts in everyday language. Metaphor is the act of understanding and experiencing a feeling in terms of another concept (Lakoff and Johnson (1980). A conceptual metaphor is when a 
domain is understood in relation to another (Lakoff and Johnson (1980). Those two different conceptual domains are systematically connected to each other. One domain function as "target domain" and another function as "source domain" by all means that the "target domain" is conceptualised as another. This conceptual domain can only be understood by picking up alternatives to another domain of experience (Jackel, 2002). The analysis of metaphor explains how metaphor is used, how it is conceived, and can metaphor help speakers to gain their certain discourse objectives (Cameron, 2007:108).

Pasang ri Kajang designates the messages passed down from the forefathers of Kajang people. It comprises messages of guidance, mandate, counsel, and warning or reminders (Usop, 1978). This ancient discourse is fully associated with metaphorical expressions, and in order to comprehend those expressions, we need to comprehend the concept and experiences stored in the minds of Kajang people. We knew that metaphor views differently from what people actually utter or write (Cameron, 2007:108). Pasang ri Kajang cannot be understood only by what the speakers utter but in order to comprehend the real meaning of Pasang, we must identify the context and culture in which adhere in it, as Allan (2008) reported that metaphor can be interpreted only by considering the cultural context in which they occur.

This paper aims to analyze the concept of death associated in Pasang ri Kajang well known as an ancient discourse of Kajang people by employing the conceptual metaphor theory to establish understanding the contribution of ancient discourse to metaphorical studies. Relying with this theoretical framework of conceptual metaphors, a particular conclusion was drawn by analyzing the occurrence of corpus regarding the concept of death. The final result of this research, provides a better understanding of the ancient concept of death of Kajang people.

\section{Review of Literature}

\subsection{Cognitive Linguistic Approach in Metaphor Studies}

Cognitive linguistics is an approach that is applied to analyze language in order to figure out the conceptual meaning of the language usage Lakoff and Johnson (1980). It is a contemporary approach to language analysis, language learning, and conceptual structure. Scholars and cognitive scientists employed this approach to explain metaphor phenomena. Ever since Lakoff and Johnson have introduced their ideas regarding cognitive linguistics by publishing their seminal book entitled Metaphor We Live By in 1980, researchers begin to follow their path by researching in the same course. Lakoff and Johnson (1980) claim that "metaphor is pervasive in everyday life, not in language but in thought and action". They argue that the area of metaphors are located in mind not in language. Therefore, metaphors now are considered as cognitive phenomena that appear in language. It assists to explain lots of different linguistics mechanisms (Soriano \& Valenzuela: 2005).

Numerous scholars applied cognitive linguistic approach in their studies. Hung (2019) used cognitive linguistics as his basic concepts in teaching idioms to EFL students. He then learned that students' awareness of conceptual metaphors have contributed to remembering the target items long. Lee (2015) investigates a critical metaphor analysis on 58 speeches conveyed by Singapore government leaders on the necessity of national education for national survival. Her study reveals the ideational dominance of the government in citizenship education discourse and proves against the helpfulness and value of critical metaphor analysis for critical public relations practitioners and researchers to bring out the hidden propositions in natural discourse. Others researchers Tyler et al (2011) conducted a quasi-experimental study to examine the efficacy of applying a 
cognitive linguistic approach to instruct L2 learning of the semantics of English to, for and at. It reveals that advanced learners who received instruction based on a cognitive linguistic perspective experienced substantial improvement in their understanding of the semantics of those three prepositions.

\subsection{Conceptual Metaphor Theory}

Metaphors as the cognitive phenomenon have been studied in many disciplines, namely linguistics, literature, sociology, as well as philosophy. Those studies are conducted mainly from the cognitive perspective (Zhao et al, 2020:122). Lakoff and Johnson $(1980,1999,2003)$ argue that conceptual metaphor is the understanding of a domain in terms of another. Furthermore, they stated that the numerous utterances used in our daily communication are metaphorical.

The conceptual metaphor comprises two semantic domains known as the target and source domains. The "source domain" is characteristically concrete, while the "target domain" comprises abstract ideas (Lakoff and Johnson, 1980). These two domains are systematically linked with mappings. Based on the cognitive perspective of metaphor, people gain understanding of one conceptual domain with respect to another (Lakoff and Johnson, 2003). This means that abstract concepts are used to understand concrete ideas.

Conceptual metaphors enable people to quantify, visualize, and generalize abstract concepts because they create a relationship within the source domains. This technique also enables the use of metaphors in physical experiences (Lakoff and Johnson, 1980). Kovecses (2005) reported that understanding and conceptualizing the world is based on the physical environment, which serves as a reference for the perceptions of reality.

In the past several decades, the studies of conceptual metaphors have been conducted in perspective of cognitive semiotics, and they showed beyond doubt to be an effective means in formulating cognitive and cultural experiences of men, as well as their ideology (Zhao et al, 2020:124). Consequently, numerous researchers' attention were led into this area of being conducted (Gibbs, 2014) and with no doubt to be a very gainful approach for discourse analysis. Golzadeh and Pourebrahim (2013) have examined the concept of death in the Quran and Nahjul - Balaghah, and as the results they concluded that in the religious text of the Holy Quran and Nahjul - Balagha, there was a multiplicity of metaphors for the conceptualization of death. They conclude that among personification, "DEATH IS A CALLER" or "DEATH IS A CAMER DRIVER. Another researcher, Bakhtiar (2014) investigated Iranian culture and found out that death is conceptualized as DEATH IS LIFE and DEAD ARE EMOTIONAL BEINGS. However, most of the aforementioned researches none of them examined oral discourse as their corpus, they all examined written corpus. Meanwhile, this current research investigated an oral discourse which gives us a fresh perspective in conceptual metaphor study.

\subsection{Critical Metaphor Analysis}

In order to investigate the speakers' covert power, an association is established between critical metaphor and discourse analysis, alongside pragmatics, corpus and cognitive linguistics. The concept of Critical metaphor analysis (CMA) encompasses the significant enrichments applied in Conceptual Metaphor Theory and Critical Discourse Analysis (Charteris - Black, 2004). CMA is a metaphoric approach used to reveal a language users' hidden intention (cognition) and also prompt the development of readers' awareness in the aspect of social relations, using metaphoric expressions (Charteris Black, 2004). The framework used to analyse metaphor must consist of linguistic, 
semantic, cognitive, and pragmatic criteria for proper expression (Charteris and Black, 2004).

CMA comprises three steps: Identification, interpretation, and explanation of conceptual metaphors. (1) Identification is the use of a sample of texts to determine candidate metaphoric expression, (2) Interpretation involves establishing relationships between metaphors, alongside the pragmatic and cognitive elements applied during the determination of conceptual keys. The conceptual metaphor plays a major role in resolving the semantic tension existing between metaphors, while conceptual keys simultaneously deciphers the tension amongst conceptual metaphors, (3) Explanation is relevant in the identification of social agencies involved in producing metaphoric expressions. The formation of conceptual metaphors aids in explaining the use of persuasive illustrations (Charteris and Black, 2004). Cameron \& Low (1999) state that explanations are used to reveal the understanding of thought as well as the patterns used to construct people's beliefs and actions.

\subsection{The Concept of Pasang ri Kajang}

Pasang ri Kajang is a set of messages inherited from the Kajang ancestors. It is an ancient oral discourse known as patuntung and the guidance of life for the Kajang community (Ammatoan). Pasang contains ancient messages regarding guidance, mandate, counsel, and warning or reminder. According to Lureng (1980), it is a tradition and system of knowledge that contains the values of a culture under the guidance of Ammatowa (a tribe chief). Akib (2008) stated that Pasang ri Kajang is the way of life of the Kajang people that guides and guards their way of life. Kajang people consider Pasang as a guide for human beings in all aspects, in social, religious, livelihood, culture, environment, and leadership system. It is considered as the only source and knowledge of how to live life.

Pasang has been studied by a number of researchers, they discuss various aspects contained in Pasang based on their interest in studies. In relation to conceptual metaphor, it is fully metaphorical expressions, therefore to comprehend it, we should be able to sense the cognition of speakers by employing conceptual metaphor theory to analyse them, since metaphor is a cognitive instrument used to conceive of our world (Lakoff and Johnson, 1980). This current study is the first time that Pasang ri Kajang was analysed by employing metaphor conceptual theory and an approach of conceptual metaphor analysis.

\section{Research Methods}

This study is a qualitative research, which uses an ethnographic approach. It applies CMA to analyze the metaphors found in Pasang ri Kajang. CMA applies to identify the intention (cognition), ideologies, and socio-culture of Kajang people. This research was conducted in Tana Toa village (ilalang embayya) located at Bulukumba regency in South Sulawesi province, Indonesia.

The data were taken from 25 people as the correspondents of this research. These people are very respective members of the community that plays essential roles such as the Ammatowa (the leader of Kajang community), Galla (chief assistants), culturists of Kajang and those with an adequate understanding of the Pasang. The triangulation method was employed for data validation. This triangulation method involves different sources of information to increase the data validity of the study.

Data was collected through observation, semi-structured interviews, field notes, and recording. They were collected qualitatively using the strategy of semi-structured interview, where informants were asked a string of predetermined and open-ended 
questions. During this process, field notes are taken to record all experiences and observations made by the researcher. The recording process was one way to record data taken from the community of interpreters during the interview process. Meanwhile, notetaking was employed to write down all the relevant data during the interview.

The techniques used to analyze data are arranged in the following three stages:

1. Data Identification: The candidate metaphors were examined in relation to the specified criteria. It is used to determine the tension between a source and a metaphoric target domain. It comprises three metaphorical criteria: linguistic, pragmatic, and cognitive (Charteris and Black, 2004). It includes two main stages. The first takes a close careful reading of the text (Pasang) to identify candidate metaphors found in Pasang ri Kajang. The second stage identifies the keywords, consisting of Linguistic, pragmatic, and cognitive phrases (Charteris - Black, 2004:35).

2. Data interpretation: This stage establishes a relationship between metaphors along with the cognitive and pragmatic features. (Charteris and Black, 2004). It is concerned with the interpersonal meaning used to identify the type of social relations associated with the constructs.

3. Data explanation: This stage determines the involvement of social agency associated with the formation of conceptual metaphors, and keywords. (Charteris and Black, 2004). It is also concerned with the way metaphors are interrelated with reference to the underlying condition.

\section{Discussion}

\subsection{The Conceptualization of Death Is a Journey}

Conceptualization of DEATH IS A JOURNEY associated with understanding the principle of death. In this analysis, metaphors are used to map and transfer different attributes from the source domain (JOURNEY) to the target (DEATH). Death is a metaphysical phenomenon, while journey is the act of traveling from one place to another. The human knowledge on journey is used to map death, and this conceptual metaphor is used to define Pasang as follows:

Corpus (32) : Hajik tojeki matea paklingkaanga rianja rakjingi rolo nampa lumbak balasakna.

$\mathrm{MB}^{1}$ : Hajik/toje-ki/mate-a/ pak-lingka-nga/ ri-anja / rakjing-i/

PS $^{1} \quad$ : Adj.good/Indeed/death /NOM.journey /Prep.hereafter/Adj.difficult/

$\mathrm{MB}^{2}$ : rolo/ nampa/ lumbak/balasak-na

$\mathrm{PS}^{2} \quad:$ first / then / easy /N. reward.POSS.

LT : Good /indeed / death /is journey /to hereafter/ difficult /first/ then/ easy/ on its reward.

IT : Kajang people believe that only the death of good people deserves to journey to the hereafter.

Corpus (33): Tala jammengi matea aklikanaja ri anja iyaji jammeng nungtaklea ri jampea.

$\mathrm{MB}^{1} \quad$ : Tala/ jamming-i /mate-a/ aklingka-na-ja/ ri /anja / iya-ji/

$\mathrm{PS}^{1} \quad$ : None/ soul /death / journey ACT./Prep/hereafter/only/

$\mathrm{MB}^{2}$ : jamming/nung-tak-lea/ ri / jampea.

$\mathrm{PS}^{2}$ : soul /Neg. Find /Prep./grave.

LT : None/the soul / of death/ journey /to hereafter/only/the soul/not found /in /grave

IT : Death is a process of separating the soul or spirit from the physical body. 
Corpus (34): Lino pammari - pariangji, ahera pammantangngang karakrakkang.

MB : Lino/pang-mari-mari ang-ji, /ahera /pang-mantang-nga/ka-rakrak-ang.

PS : world / temporary ACT.only /hereafter/ NOM.stay /forever

LT : World /temporary only / hereafter/ is place to stay / forever

FT : Life in this world is temporary, and forever in hereafter

Table 1. Mapping for DEATH IS A JOURNEY

\begin{tabular}{ll}
\hline Source: JOURNEY & $\Rightarrow \begin{array}{l}\text { Target: DEATH } \\
\text { place (hereafter) }\end{array}$ \\
\hline Jammeng (Sailing/ Journey) & $\Rightarrow \begin{array}{l}\text { Death is the act of entering eternal } \\
\text { life in the hereafter. }\end{array}$ \\
$\begin{array}{l}\text { Paklingkaang } \\
\text { (Go/Leave) }\end{array}$ & "Lingka" $\Rightarrow$ a particular \\
\hline
\end{tabular}

In the Kajang community, when someone passes away, drums (Palingoro) are beaten to inform others of the death. For three months and ten days, various activities are carried out by the grieving family. The dead body is usually handled by a person with magical powers called (tu paruru tu mate). Before performing the ritual, the family has to decide on types they need, based on their financial ability and social status. There are three types of death ritual namely akdampok for the wealthy, a'lajo - lajo for the middle class and dangang biasa for commoners. Assuming a family decides to perform a'lajo - lajo, they do not need to state the dead person "e original descendants. However, if they want to conduct the akdampok death ritual, they have to state their original descendants. This symbolizes that their social and financial status met the requirements for this type of ritual. The Ammatoans are mandated to wear black clothes which consist of tope (sarong), passapu (headband), black shirt for men, and black blouses and sarongs for women to attend the ritual. Ammatowa, as the customary leader, is expected to participate in the ritual; however, in situations where they are unable to attend, they may appoint one of the customary apparatus.

The concept of death to the indigenous communities has very significant meaning because life hereafter is immortal. Their acts and deeds on earth are rewarded hereafter by God Almighty (Tau Riek Akrakna) in accordance with the quality of these acts and deeds. Therefore, they need to prepare themselves before death. The lexical meaning of the word Jammeng (in corpus 33) means someone willing to sail to a particular place. While the word Paklingkaang (also in corpus 33) is derived from the word Lingka which means go or leave. Ammatoan believes that only a good death travels or journeys to the hereafter (Maruf, 2018). These two lexical items correspond to this conceptual association of journey as a source domain.

A keyword of conceptual metaphor is embodiment (Lakoff and Johnson, 1980; 1999), therefore, metaphor is constructed and understood through the basis of experience (bodily, physical experiences, or social and cultural experiences). The result confirmed that Pasang ri Kajang as the ancient messages from the ancestors of Kajang people fully contain metaphorical phrases, it can only be understood by social and cultural experiences which are embodied in everyday life. This relation between language and experiences in everyday life verify that metaphor is a cognitive tool to comprehend the peripheral realism (Lakoff and Johnson, 1980).

As noted in the result above that conceptual metaphor DEATH IS A JOURNEY is a manifestation of belief of Kajang people who consider death is an act of entering immortal life, death is a journey into eternal life in hereafter and death is a process of separating the soul or spirit from the physical body in which only death of good people deserves to 
journey to the hereafter. These intimate concepts of death cannot be disassociated from culture. Culture and cognition of Kajang people influenced the creation of Pasang, therefore, in order to comprehend the real meaning of the metaphorical expressions or metaphorical concepts that lie in Pasang, one must know the concept and culture in which the metaphor it appears. If the concept or context and culture are not known, then the interpretation of the real meaning in a metaphor can be wrong or misinterpreted (Searle, 1979:85).

In addition, Levinson cited in Charteris - Black (2004:10) argues that interpretation of metaphor relies on the ability to think analogically. Related to this statement, the conceptual metaphor of DEATH IS A JOURNEY is formed by a couple of key words occur in Pasang function as analogies such as the word "Jammeng" means someone desires to sail to a particular place, and the word "Paklingkaang" (in corpus 33) which derived from the word Lingka means go or leave. These two words analogically mean that the death of a good person sails to hereafter and death is the act of entering the eternal life of hereafter.

\section{Conclusion}

Based on the results of this study, the following conclusions can be drawn:

The conceptual metaphor DEATH IS A JOURNEY reveals that the concept of death to people of Kajang has a very significant meaning. They believe that life on earth is mortal life, and actions during life on earth will be rewarded with extraordinary wealth (Kalumannyang kaluppepeang) in hereafter by God Almighty (Tau Riek Akrakna) according with the quality of acts and deeds. They consider life in the world is a process of journey to enter eternal life (karakkang) in the hereafter.

Despite the extensive studies on conceptual metaphors and Pasang ri Kajang during the last decades, this research is the new thing that Pasang ri Kajang is analysed by incorporating both cognitive and critical metaphor analysis to reveal the concept of death found in Pasang. This study provides a good view on how to comprehend Pasang in different ways and may contribute to conceptual metaphor study in discourse analysis especially in ancient oral discourse.

The limitation of this research should be considered. The corpus examined in this research was very limited since the scope of the research only regards the concept of death, meanwhile in Pasang itself consists of thousand messages in the form of oral discourse. Thus, it is suggested that further research examine Pasang through various aspects of life.

\section{References}

Akib, Y. (2008). Ammatoa, komunitas berbaju hitam. Makassar: Pustaka Refleksi.

Allan, K. (2008). Metaphor and metonymy: A diachronic approach. Chicjester, West Sussex, U.K: Malden, MA: Willey - Blackwell.

Bakhtiar, M. (2014). Metaphorical eternity in action: The nonlinguistic realization of death metaphors in Iranian culture. Cognitive Linguistic Studies, 1(2), 252-270.

Cameron, L., \& Low, G. (1999). Researching and applying metaphor. Cambridge: Cambridge University Press.

Cameron, L. (2007). Annual Review of cognitive linguistics 5, 107-135. ISSN 1572-0268 / e-ISSN.1572-0276: John Benjamins Publishing Company.

Charteris, Black. (2004). Corpus approaches to critical metaphor analysis. New York: Palgrave Macmillan. 
Evans, V. \& Green, M. (2006). Cognitive linguistics. An introduction. Edinburgh: University Press.

Gibbs, Jr. Raymond W. (2014). Conceptual metaphor in thought and social action. In Mark J. Landau, Michael D. Robinson \& B. P. Meier (eds.), The power of metaphor: Examining its influence on social life. Washington, DC: American Psychological Association.

Golzadeh, F. A., \& Pourebrahim, S. (2013). Death metaphor in religious texts: A cognitive semantics approach. The International Journal of Humanities, 20(4), 61-78.

Hammersley, M. (1992). What's wrong with Ethnography? London: Routedge.

Hung, B.H. (2019). A Cognitive linguistic approach to teaching English Idioms to EFL Students: Experimental Results. 3L: Language, Literature, and Linguistics. The Southeast Asian Journal of English Language Studies - Vol 25(2): 113 - 126. http://doi.org/10.17576/3L-2019-2502-09

Hutchins, Edwin. (2014). Material anchors for conceptual blends. Journal of Pragmatics 37(10). 1555-1577.

Ivanovic, I. (2017). Comparative study of metaphor in British and United States of America (US) political discourse. XLinguae Journal, Volume 10 Issue 2, April 2017, ISSN 1337-8384.

Javier, V. \& Cristina. (2005). Cognitive metaphor and empirical methods. Barcelona Language and Literature Studies. Pp.3.

Kövecses, Z. (2005). Metaphor in culture: Universality and variation. New York: Cambridge University Press.

Lakoff, G \& Johnson M. (1980). Metaphor we live by. Chicago: Chicago University Press.

Lakoff, G \& Johnson, M. (1999). Philosophy in the flesh: The Embodied Mind and Its Challenge to Western Thought. New York: Basic Books.

Lakoff, G \& Johnson M. (2003). Metaphor We Live by. Chicago: Chicago University Press. 2nd ed.

Lee, M (2015). Critical Metaphor Analysis of Citizenship Education Discourse. Public Relation Inquiry, 4(1), 99 - 123.http://dx.doi.org/10.1177/2046147X14559934.

Levinson, C. Stephen. (1983). Pragmatic. Cambridge. Cambridge University Press.

Lureng, G. (1980). Pasang ri Kajang: Suatu pendekatan dari segi antropologi. (Unpublished Ph.D Thesis). Postgraduate Program, Hasanuddin University, Universitas Hasanuddin. Makassar.

Maruf, N. (2018.) A Conceptual metaphor study in Pasang ri Kajang to reveal the cognition, ideologies, and socio - culture of kajang people. (Unpublished Ph.D. Thesis). Universitas Hasanuddin. Makassar. Indonesia.

Jäkel, Olaf. (2002). Hypotheses revisited: The cognitive theory of metaphor applied to Religious Texts. In metaphorik.de 02/2002, p. 20 - 42.

Ospanova, Z., Tolybayeva, K., Nurkenova, S., Duisekova, K., Baltabayeva, G. (2020). Lingua and culture study research on indirect communication cognitive metaphor. In Xlinguae, Vol. 12. N. 2, pp. 157 - 165. ISSN 1337-8384.

Ross, W. D. (1952). The works of aristotle. Oxford: Clarendon Press.

Searle, John R. (1979). Expression and meaning. Cambridge: Cambridge Science 11: 93 116.

Tyler, A. Mueller, C., Ho, V. (2011). Applying cognitive linguistics to learning the semantics of English to, for and at: an Experimental Investigation. Vigo International Journal of Applied Linguistics (VIAL) 8. 181 - 205.

Usop, K. M. (1978). Pasang ri Kajang: ajian Sistem nilai di "benteng hitam" Ammatoa. Ujung Pandang, Indonesia: Pusat Latihan Penelitian Ilmu -Ilmu Sosial, UNHAS. 
Valenzuela, J., \& Soriano C. (2005). Cognitive metaphor and empirical methods. Barcelona Language and Literature Studies. 1-19.

Zhao, X., Shen, R., Zhao, X. (2020). A cognitive - semiotic construal of metaphor in discourse. DOI 10.1515 / css - 2020-0006: In Chinese Semiotic Studies 16 (1): p. 119-143. 